\title{
A TRANSIÇÃO DO DRAMA BURGUÊS PARA O DRAMA NATURALISTA
}

\author{
Bárbara Ferrario Lulli \\ Universidade Estadual Paulista (UNESP) - FFC
}

O objetivo deste trabalho é apresentar como se deu a passagem do drama burguês para o drama naturalista. Historicamente o drama burguês se situa no século XVIII e encontra seu auge no momento que a burguesia sobe ao poder após a Revolução Francesa. Nesta época, o drama burguês assume para si as características principais do gênero dramático como um todo, destacando-se como elemento principal o diálogo, enquanto expressão das vontades de cada indivíduo, denominado por Peter Szondi como relações intersubjetivas. O drama naturalista, por sua vez, surgiu historicamente no momento que os valores da burguesia já não mais se sustinham, o que se refletiu diretamente na literatura e no teatro, possibilitando que o drama naturalista entrasse em cena com heróis pertencentes às classes mais baixas da sociedade. Diferente do drama burguês, a ação dramática naturalista deixou de ser constituída pelas relações interpessoais, uma vez que o comportamento das personagens naturalistas se condiciona pelas determinações sociais e biológicas. Analisaremos, portanto, as características do drama burguês e do drama naturalista, destacando as principais distinções entre os gêneros, tal como a transição de um para outro.

$* * *$

Com as suas expansões econômicas, a burguesia passou a defrontar-se diretamente com a nobreza buscando o mesmo posicionamento social e o reconhecimento político e econômico. Esta ascensão socioeconômica pôde ser vista também nas artes, todavia, tendo acesso à cultura, o espectador burguês passou a aspirar no teatro seus próprios anseios, com isso, nota-se uma intensa busca pela sensibilidade que, por um lado, 
emocionasse o público, por outro, fizesse-o refletir sobre os problemas morais da sociedade. O objetivo da burguesia era, pois, representar os valores em que sua classe se assentava.

Sendo assim, instituem-se no drama burguês os valores da burguesia como a família e o trabalho, com ênfase na subjetividade do indivíduo. No drama burguês não se instaurava o determinismo social; o homem é fruto dos seus próprios hábitos e se distinguem entre si pelo poder aquisitivo e pela influência exercida perante a comunidade. Como no mostra a passagem a seguir:

O novo gênero requereria também novos assuntos: suas peças se baseariam, não nas peculiaridades de um personagem individual, mas em papéis sociais e familiares - as preocupações sobre a classe média. O homem de negócios, o político, o cidadão, o administrador público, o marido, o irmão ou a irmã e o pai de família poderiam agora servir como centro de um drama. (CARLSON, apaud D. Diderot, Oeuvres completes, 1969, 13v., v.1, p. 637)

A relação direta entre os indivíduos institui o diálogo aproximando-se da realidade representada, assim, tal diálogo passa a se destacar dentro da nova estrutura adquirida para o drama burguês. Além disso, por não haver um narrador no drama, os encarregados pela função de desenvolver o desenrolar das cenas são as personagens que se envolvem em tramas variadas através das relações e que expõem de maneira compreensível a ação dramática. Para que isso aconteça é fundamental o entrechoque de vontades que se externam através do diálogo - do subjetivo do indivíduo para a sociedade - e, a partir desse embate, cria-se uma relação dentro da qual as ações dramáticas surgem, interagem e influenciam umas às outras.

A trama cênica, por sua vez, é usada de modo a fazer com que o público se depare com a realidade da sociedade nos palcos, o que pode ser constatado não apenas na trama, mas também nas personagens que expressam sua subjetividade em relação à um determinado âmbito comum à todos. Essas características revelam-se como atrativo ao espectador que passivo "assiste à conversão dramática: calado, com os braços cruzados, paralisado pela impressão de um segundo mundo." (Szondi, 2001, p.31). Por isso, é retratado no drama burguês o ambiente familiar, o trabalho e os assuntos de interesse da classe, para que cada espectador se envolva intimamente com a peça, pois "sua 
passividade total tem (e nisso se baseia a experiência dramática) de converter-se em uma atividade irracional: o espectador era e é arrancado para o jogo dramático, torna-se o próprio falante (pela boca de todas as personagens bem entendido).” (Szondi, 2001, p.31).

Como mostramos, o teatro foi adequando-se aos temas ligados à preocupação da nova classe média, dessa forma, as circunstâncias da vida intima diária retratava a moralidade com a intenção de fazer do teatro um instrumento pedagógico capaz de instruir a população, assim:

Moralidade e verossimilhança seriam mais bem servidas, sugere Diderot, por um novo gênero, (...) que pintaria as paixões e as circunstâncias da vida doméstica diária." (Carlson, 1997, p. 149).

Após a Revolução Francesa, os novos valores de igualdade, fraternidade e liberdade tornaram-se recorrentes nas peças, assim como o patriotismo. O teatro era visto como um instrumento educacional pela capacidade de atingir boa parte da população, visto sua capacidade de incitar o sentimento de identificação entre as personagens e o espectador. Por isso, era necessário que os assuntos dispostos em cena inspirassem os valores e incriminassem os vícios da sociedade:

O auditório do teatro é o único lugar onde as lágrimas do homem virtuoso e as do pecador se misturam. Ali o pecador sente-se pouco à vontade com a injustiça que cometeu, sente pesar pelos males que praticou e se indigna com o homem de seu próprio tipo. (CARLSON, apaud, Diderot, Oeuvres completes, Paris: 1969, 13v., v.1, p.637).

Após a Revolução Francesa, esperava-se encontrar no teatro - principal distração da população burguesa - temas com conteúdo referente a sua própria história, assim, o drama passa a instaurar-se como modelo crítico de sua época. Os valores apresentados nas obras deste período e as estruturas da dramática pura (as unidade de tempo e espaço) já não refletiam mais a evolução histórica do homem. Rompe-se, dessa maneira, as características que vigoravam na dramática pura e, com isso, o drama passa a representar o homem mostrando sua própria evolução histórica. É neste momento que surge o drama naturalista.

O drama naturalista, de maneira distinta do drama buguês, se assenta num novo alicerce, a saber, aquele que toma por princípio a forma fiel do homem comum determinado pela sua natureza. "É o novo estado social, nascido da Revolução, que fixa 
pouco a pouco uma nova fórmula dramática, no meio de tateios, de passos dados para frente e para trás." (Zola, 1982, p.110). A tradição naturalista na segunda metade do século XIX foi assim, representada pelas novas concepções à respeito da natureza do homem e da vida em sociedade. O naturalismo representou o retorno à natureza e ao homem: a observação e a aceitação exata do que existe. Assim, na literatura e no teatro não se permite mais representar o que não seja exato e real a respeito do homem, ou seja, esta tradição permite apenas que as personagens sejam retratadas de maneira concreta, pois, elas não são "mais invenções mentirosas, não mais absoluto; porém, personagens reais, a história verdadeira de cada um, o relativo da vida cotidiana." (Zola, 1982, p.92)

A abordagem sucinta da exata realidade humana no drama naturalista surge de um nova condição social, que deve representar as situações econômicas e políticas dramaticamente impulsionadas à vida coletiva. O dramaturgo deve exibir, também, fatores enraizados do sujeito que determinam seu estado emocional e subjetivo. Assim, a representação dramática dessas relações consiste em contrapor o estado de "condicionamento em intersubjetividade" (SZONDI, 2001), ou seja: fazer com que a situação coletiva - socioeconômica e biológica - constitua a subjetividade de cada indivíduo que vai do objeto ao sujeito; caminho contrário do drama até então.

Como vimos, o drama burguês detinha-se a contraposição de vontades das personagens, se desvinculando do que lhe é externo. Com toda a sua temática formulada em torno do intersubjetivo, instituía-se o diálogo como mediador das relações. Neste aspecto, a dramática naturalista contraria a exigência absoluta própria da forma dramática pois representa-se personagens condicionadas, sem poder de ação "em que a existência se revela como o vácuo do Nada - personagens que vivem no passado saudoso ou no futuro sonhado, mas nunca na atualidade do presente..." (Rosenfeld, 1985, p.92). O diálogo por sua vez, perde esta função, pois adquire a forma lírica, já que a troca superficial de comunicação revela estados emocionais condicionados pelo meio, ou seja, o diálogo transforma-se em monólogo, sendo somente a expressão da personagem sem antagonistas já que estão nas mesmas condições econômicas-sociais.

O que se nota são as transformações, não o discurso do tempo condicionado por elas. Todavia, quando não há transformações mas apenas a monotonia cinzenta do tédio, é o próprio tempo vazio que passa a ser focalizado e no mesmo momento o tempo se coagula. (Rosenfeld, 1985, p.92) 
Para exemplificar, nos utilizaremos da peça Os Tecelóes (1891) do dramaturgo naturalista Gerhart Hauptmann. De modo geral, a peça apresenta a história da vida precária dos tecelões da Silésia (1844), mostrando como a situação socioeconômica desencadeou a trágica revolta dos tecelões. Esta peça carrega traços vigentes do naturalismo com acentuadas características da nova forma dramática. $\mathrm{O}$ diálogo, como já dito, se dissolve no drama naturalista em uma série de comentários e monólogos, já que a ação dramática não depende mais das vontades subjetivas externadas, sendo assim, a necessidade de expressar-se em meio a sociedade, desaparece. No naturalismo, portanto, a ação dramática se cria por conta do condicionamento determinista da classe operária. Em monólogos, as personagens externam suas aflições, o que se caracteriza com um traço estilístico lírico, expresso na seguinte passagem:

MÃE BAUMERT - Como vão as coisas em casa, Sra. Heinrich?

SRA. HEINRICH - (Explode desesperada.) Juro que logo não aguento mais. [...]

MÃE BAUMERT - Para nós, Sra. Heinrich, seria melhor se o bom Deus tivesse misericórdia e nos levasse desse mundo.

SRA. HEINRICH - (Fora de si, exclama soluçando.) Meus pobres filhos vão morrer de fome! (Soluça e geme.) Não sei mais o que fazer. Posso fazer o que quiser, correr até não aguentar mais. Sinto-me mais morta que viva, e nada se modifica. [...] (Hauptmann, 1968, p 27-28.)

Como pode-se perceber, não se trata de um diálogo, isto é, a trama não se desenvolve a partir de um conflito, o que ocorre é a descrição da condição das personagens. Outra característica que o drama naturalista rompe é a forma da peça fechada em si, caráter absoluto da dramaturgia. N'Os Tecelões surge em cada ato novos cenários e personagens sem uma unidade de progressão entre os acontecimentos.

DREISSINGER - O que é que você quer, afinal?

TECELÃO HEIBER - O adiantamento que, na última vez, quero dizer, uma vez que...

DREISSIGER - Bem, não estou entendendo nada. TECELÃO HEIDER - Estava em dificuldade porque... DREISSIGER - Isso é com o Pfeifer, isso é com Pfeifer. Realmente não posso. Acertem isso com Pfeifer. [...] PFEIFER - (Reiniciando a inspecção dos tecidos.) Então Anna, o que traz você?

O VELHO BAUMERT - Qual então o preço do tecido, Sr. Pfeifer? 
PFEIFER - Dez moedas de prata, cada um. O VELHO BAUMERT - Como vai indo bem.

(Movimentação por entre os tecelões, cochichos e resmungos.)

O PANO CAI. (E inicia-se o segundo ato.)

(Hauptmann, 1968, p. 22-23)

A cena acima descreve uma típica situação corrente nas peças naturalistas: o diálogo se inicia e logo se dissipa, além disso, o ato se encerra abruptamente sem que a cena se conclua. Outra característica da concepção naturalista é conceber o homem como determinações de forças exteriores imutáveis e inarticuláveis, e desconstruindo assim, a ação livre, como no seguinte exemplo:

VOZ - (Da casa.) Saia da janela, pai Hilse!

VELHO HILSE - Eu não! Nem que todos vocês fiquem completamente malucos. [...] Aqui me colocou o Pai Divino não é, Mãe? Aqui continuamos sentados, cumprindo o nosso dever, nem que a neve seja toda consumida pelas chamas. (Hauptmann, 1968, p. 120)

O quinto e último ato, apresenta o conflito dos tecelões contra seus senhores, porém a situação se divide entre tecelões e os donos das fabricas, dessa forma, o entrechoque não é absoluto, pois não está submerso na mesma classe social. O que há é o esboço de personagens que encontram-se em um estado simultâneo, mas sem comunicação e sem antagonismo dado que a situação é monótona. Segundo Anatol Rosenfeld, aos Tecelões “aplica-se a esta forma o que Alfred Doeblin disse da obra épica: ela poderia ser 'cortada pela tesoura em vários pedaços que ainda assim, se mantem vivos como tais"”. (Rosenfeld,1985, p.96).

A tradição naturalista foi considerada a arte da representação fiel da vida humana em suas próprias fontes, e assim sendo, não há motivo para representá-lo de outro modo quando sua essência emana da sua própria natureza. Para Émile Zola, grande defensor da escola Naturalista, "isso prova simplesmente que ele (naturalismo) provém das próprias entranhas da humanidade, (...); nada é estável numa sociedade, tudo se acha conduzido por um movimento continuo" (Zola, 1982, p.122).

Na fórmula do drama naturalista é circunstancial a passagem pelo meio; o homem deixa de ser uma "abstração intelectual" e corresponde agora, há um "animal pensante" (Zola, 1982) que não se separa da natureza, e consequentemente, recebe as 
influências do lugar onde vive. Dessa mesma forma, o dramaturgo naturalista não separa a personagem da sua atmosfera, pois encontra em seu ambiente grande importância, isto é, deixa de descrevê-la "por uma necessidade de retórica, [...] nota simplesmente, a cada hora, as condições materiais nas quais agem os seres e se produzem os fatos, com o fito de ser absolutamente completo, de abranger em sua investigação o conjunto do mundo e de evocar a realidade inteirinha." (Zola, 1982, p.131).

Outra diferença do drama burguês para o drama naturalista são os cenários. Eles devem evocar e pôr no palco a realidade dos meios; isso cabe também aos dramaturgos: fornecer as descrições exatas de seu tempo, características que não são somente necessárias mas que apresentam-se como condição essencial de seu tempo, pois o naturalismo "é o retorno à natureza e ao homem, a aceitação e a pintura do que existe" (Zola, 1982, p.92), sendo assim, deparamo-nos com um fator de grande crítica da forma da dramática pura para com o naturalismo: se o poeta naturalista deve captar somente a verdade, seu tempo, de certo modo, retrata o presente.

Por fim, as personagens no drama naturalista se espelham sempre em heróis das camadas baixas da sociedade, pois são estes os que carregam a "força de vontade inquebrantável” (Szondi, 2001, p.101) para lutarem contra sua própria limitação determinada. Este elemento, vigora como principal diferenciação entre o drama burguês e o drama naturalista. Com a ascensão econômico-social, a burguesia deixou de ter em si o elemento dramático que a capacitou de suster o drama por um longo período: sua luta e busca pela autonomia participativa na sociedade. Por isso, novos temos surgem: o voto para mulheres, amor livre, direito de divórcio, industrialização e socialismo. Tais lutas são expressas n'Os Tecelóes como a imposição crescente da mulher na sociedade:

UM SEGUNDO TECELÃO - (Perplexo.) Agora vejam as mulheres, vejam só as mulheres! Não é que estão levantando as saias! Não é que estão cuspindo nos soldados! (Hauptmann, 1968, p. 119)

O processo de transição do drama burguês para o drama naturalista, como vimos, foi caracterizado pela mudança no que concerne a estrutura da trama, do diálogo, das personagens, do enredo e, principalmente, pela forma como as relações dentro do drama se estabelecia. Essa passagem dos gêneros corresponde à transição histórica no período moderno, isto é, da ascensão da burguesia aos movimentos das classes baixas da sociedade. 


\section{REFERÊNCIAS BIBLIOGRÁFICAS}

CARLSON. M. Teorias do teatro: estudo histórico-crítico, dos gregos à atualidade. São Paulo. Ed. Unesp, 1997.

HAUPTMANN. G. Os tecelões. São Paulo: Ed. Brasiliense, 1968.

ROSENFELD. A. O teatro épico. São Paulo: Ed. Perspectiva, 1985.

SZONDI. P. Teoria do drama moderno. São Paulo: Ed. Cosacnaify, 2001.

Teoria do drama burguês. São Paulo: Ed. Cosacnaify, 2004.

ZOLA. E. O romance experimental e o naturalismo no teatro. São Paulo. Ed. Perspectiva, 1982. 